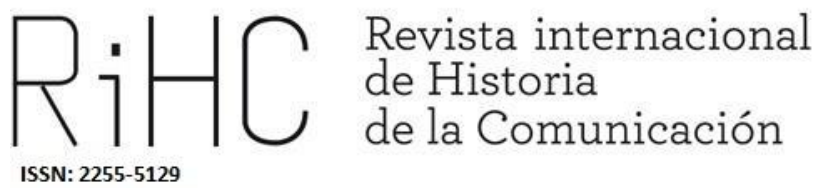

\title{
LA MEMORIA HISTÓRICA DEL CONSUMO EN COSTA RICA (1930)
}

The historical memory of consumption in Costa Rica (1930)

DOI: https://dx.doi.org/10.12795/RiHC.2020.i14.07

Recibido: $13 / 03 / 2020$

Aceptado: $12 / 05 / 2020$

Publicado: $15 / 05 / 2020$

Patricia Vega Jiménez

ORCID (D) 0000-0001-5445-8701

Universidad de Costa Rica, Costa Rica

patricia.vega@ucr.ac.cr 
Resumen: Este texto tiene como objetivo analizar la evolución histórica de los anuncios de medicamentos publicados en el Diario de Costa Rica en el mes de enero de 1930. Se categorizaron la totalidad de avisos comerciales (1701) publicados en el periódico ese mes, 927 de los cuales son de medicamentos. Aplicando el análisis contextual como herramienta metodológica, se pretende conocer la dinámica social a través del prisma de los anuncios comerciales de medicamentos. Se constata en el análisis que los anuncios responden a necesidades de la población en materia de salud, favoreciendo así la venta y consumo de remedios. De hecho coincide la presencia de la enfermedad con un aumento de la oferta de medicamentos proponiendo sanar el mal.

La mayoría de los productos medicinales que se anunciaban carecían de fundamentación científica y aprovechaban la ignorancia y la irresponsabilidad de los consumidores para exhortar la aplicación o ingesta de las pócimas que prometían cura inmediata y definitiva a todos los males.

Palabras clave: prensa, medicina, consumo, historia, publicidad.

Abstract: The objective of this text is to analyze the historical evolution of drug advertisements published in the Diario de Costa Rica in the month of January 1930. All the commercial advertisements (1701) published in the newspaper that month, 927, were categorized of which are from medications. Applying contextual analysis as a methodological tool, it is intended to know the social dynamics through the prism of commercial drug advertisements. The analysis shows that the advertisements respond to the population's health needs, thus promoting the sale and consumption of remedies. In fact, the presence of the disease coincides with an increase in the supply of medicines, proposing to heal the disease. Most of the advertised medicinal products lacked scientific basis and took advantage of the ignorance and irresponsibility of consumers, to urge the application or intake of potions that promised an immediate and definitive cure for all ills.

Keywords: Press, medicine, history, consumption and advertising.

\section{Introducción y metodología}

En 1930, los anuncios comerciales que divulgaban los periódicos ofreciendo medicamentos, prometían cura inmediata a las personas que sufrían artritis si ingerían diariamente URODONAL. Ese medicamento era efectivo también contra "reumas, arteroesclerosis (sic), obesidad y cálculos... (y resguardaba) con toda certitud de los ataques de gota... o de cólicos néfreticos (sic). Los síntomas que alertaban del sufrimiento de esos males, era el cambio del color de la orina, por ello recomendaban que "tan pronto como las orinas aparecen rojas o contienen arenillas, al primer dolor cuando crujen las articulaciones, se debe sin tardar tomar URODONAL" (Diario de Costa Rica, 5-1-1930, p. 2). 
Por su parte, quienes padecían influenza o resfriados, tenían como alternativa las pastillas orientales que "alivian como con la mano" o con las píldoras OK, "de Gómez Plata" que ofrecía la misma solución. Los problemas digestivos podían sanarse por completo ingiriendo las pastillas del Dr. Richards que resultaban la alternativa perfecta pues además, aseguraban un agradable sueño (Diario de Costa Rica, 5-1-1930, p. 5).

La promoción en los periódicos de medicinas mágicas capaces de curar en corto plazo cualquier padecimiento, es una constante en la prensa costarricense del siglo XIX (Vega, 1995: 189, 2008: 55, 2012: 35, Marin, 1995) y al menos en los primeros 30 años del siglo XX. De hecho la cantidad de anuncios de medicamentos superan en mucho, la oferta de otros bienes o servicios.

Esta particularidad se explicaría por el hecho de que la salud, el temor a la enfermedad, al sufrimiento y el miedo a la muerte, han inquietado a las personas desde siempre, de manera tal que la posibilidad de venta de productos que prometan soluciones a los problemas de salud, aumenta garantizando al vendedor, compradores potenciales permanentes.

La importancia de la salud y la promesa de vencer los males, facilitó también el desarrollo de una industria farmacéutica que pronto experimentó con novedosas y efectivas estrategias comunicativas, de manera tal que detectaban necesidades e intentaban satisfacerlas, o bien creaban necesidades ficticias que luego atendían.

A diferencia de lo que ocurre con el periodismo, la publicidad se convierte en el laboratorio de la comunicación persuasiva, es intermediaria entre la oferta y la demanda, una característica que los fabricantes de remedios aprovechan decididamente. A finales del siglo XIX se crearon marcas (Brandwatch, 2019) signo distintivo cuyo objetivo era identificar los productos y los servicios. Ensayaron también con mensajes que utilizan recursos cada vez más elocuentes (por tanto más convincentes) que apelan a las emociones, apegados al sistema de creencias del interlocutor.

Ciertamente, desde las últimas décadas del siglo XIX, los anuncios son elaborados por agencias competentes capaces de darle al artículo vida propia a través de una imagen y un logotipo que identifica la mercancía, independientemente de quienes la crean y del producto mismo. No se ofrece aceite de hígado de bacalao sino Emulsión Scott por ejemplo. La marca, como identificador comercial más allá de la representación visual (logo), supera los objetos (Fernández, 2011: 111).

Por lo general, el anuncio es la expresión comunicativa de un grupo social que procura vender un producto o servicio y obtener con ello grandes ganancias. Los negocios farmacéuticos producen bienes en masa que son ofrecidos indistintamente a los públicos a través de una publicidad cada vez más especializada, pero también en el mercado proliferan productos que no son resultado de la investigación científica, sino 
líquidos, pastillas o cremas que son promovidos por timadores, aprendices de brujos, curanderos, saca muelas y charlatanes. Los mismos anuncios, tanto los generados en las industrias farmaceúticas como los ungüentos falaces, son reproducidos en los periódicos de los distintos países. La sociedad de consumo no tiene fronteras (Laguna, 2018: 36).

En Costa Rica, los medicamentos se ofrecen en los periódicos desde que surgen los impresos regulares en la década de 1830. En esa primera etapa y hasta 1860, los remedios se vendían en casas comerciales que ofrecían bebidas alcohólicas. La gama de productos medicinales era escasa, por lo general se concentraba en uno o dos productos considerados "mágicos" para sanar al enfermo de cualquier mal: bálsamo anacardino y píldoras Holloway. En ese primer periodo se preferían las pócimas hechas con hiervas frescas (Vega, 1992: 115).

Después de 1860, las marcas extranjeras dominan el mercado de los remedios. Se destacan aspirina Bayer y Emulsión Scott. En particular, este último evidencia ensayos de estrategias publicitarias constantes: por ejemplo, en 1890 utiliza extensos supuestos testimonios aseverando las bondades del producto. Después de 1906, cuando se aprueba su distintivo de marca, un hombre con gorra de marinero, posiblemente noruego con un bacalao sobre el hombro, desaparece el texto casi por completo.

En 1900 y los años siguientes, se muestra un cambio en la estrategia publicitaria: se enfatiza en los beneficios que el consumidor obtiene del producto, convirtiéndolo en protagonista del anuncio. Acuden a estrategias publicitarias novedosas entonces: destacan las virtudes (exageradas) del producto, los beneficios que obtiene el usuario, apelan al miedo, echan mano de figuras famosas, al destaque de la marca, testimonios de usuarios, entre otros. Por lo general, los avisos comerciales hacia la década de 1930 iban dirigidos a públicos específicos: niños, hombres y mujeres de distintas edades y de diferentes clases sociales (Vega, 2012).

¿Cómo evoluciona la publicidad de remedios después de 1930? El objetivo de este ensayo es analizar la evolución histórica de los anuncios de medicamentos publicados en el Diario de Costa Rica, primer diario costarricense que se mantiene durante 89 años en circulación (1885-1974) (SINABI). Se seleccionó el mes de enero de 1930 dado que inicia el año y no coincide con épocas de ascenso publicitario -navidad, día de la madre, día del padre, etc.-.

La principal fuente de información que se utiliza es el Diario de Costa Rica publicado en enero de 1930.

Metodológicamente es una investigación de enfoque mixto pues combina la investigación cuantitativa y cualitativa en la que ésta última se nutre de datos cuantitativos. Cuantitativamente la muestra (el mes de enero de 1930) no pretende ser representativa pero constituye un conjunto que permite ensayar una primera aproximación al análisis de los anuncios sobre medicamentos. 
Se extrajeron del periódico todos los avisos comerciales que contenía cada ejemplar y se sistematizaron por una serie de categorías por tipo de producto (medicina, moda, autos, servicios de transporte, teatro, restaurantes, maquinaria, etc.), si se trata de un bien o servicio, los recursos iconográficos, el lema, el mensaje de venta entre otros. Los avisos que promueven la venta de medicamentos se clasificaron además por tema (mal que curan) y la presentación del producto (crema, jarabe o píldora).

Se trata de categorías emergentes que contemplaron o cambiaron las categorías a priori durante el tratamiento de los datos. Las categorías se ajustaron durante el proceso de recolección de información. Así por ejemplo, los anuncios que tratan tos, resfriados, catarro, dolor de garganta, entre otros, se clasifican en la categoría de enfermedades respiratorias. De esta manera se contemplan los criterios variables/categorías que se examinan y además, se trata de instrumentos fiables y válidos. Es fiable en tanto el estudio se puede repetir con el mismo método sin alterar los resultados. Esto es una medida de replicabilidad de los resultados de la investigación. La validez deriva del modo en que se recogió la información, ajustándose al contenido de cada anuncio y de las herramientas de análisis que se usaron (análisis descriptivo del aviso comercial y análisis contextual). Tal y como evidencia la despcripción del procedimiento, es una investigación transferible (Miguéles, 2006).

Los anuncios publicitarios son útiles para conocer qué se produce (oferta) pero también son una fuente muy conveniente para percibir las ideas, valores, situaciones sociales y tradiciones de una determinada sociedad: un reflejo de las identidades. Por tanto es preciso determinar cómo se ofrecen los productos (descripción), cuáles son los factores coyunturales, si los hay, que conducen a la promoción de determinadas mercancías en ese momento histórico (análisis contextual). Si, por ejemplo, hay una mayoría de medicamentos que prometen proporcionar energía, conduce a suponer que existía un padecimiento que provocaba abatimiento físico. De hecho, en las dos décadas anteriores a 1930 por ejemplo, la anquilostomiasis era una enfermedad frecuente en Costa Rica que se manifestaba, entre otros síntomas, por el abatimiento (Sáenz, 1955: 135). En otros términos, cualitativamente se trata en esta investigación de describir los anuncios y observar la dinámica social a través de la publicidad, como vehículo intermediario entre la oferta y la demanda, como fuente adicional para acercarse a la cultura costarricense. Por tanto, las principales herramientas metodológicas empleada en este ensayo son el análisis descriptivo y el análisis contextual. En el primero se consideró el logo o lema del fabricante, el mensaje de venta, y las imágenes por ser portadoras de significados y discursos. Con el análisis contextual se pretende entretejer el mensaje del anuncio con la coyuntura nacional e internacional. En términos de Robert Darnton (1984: 13), el análisis contextual consiste en ir del texto al contexto y del contexto al texto. 
Un estudio que usa la publicidad para identificar elementos del discurso de la modernidad y su relación con el proceso de transformación social y cultural en Costa Rica, es el de Barrantes (2028: 159), y muestra las posibilidades de la aplicación del análisis de contenido para estudiar la dinámica social.

\section{Resultados}

\subsection{Los anuncios}

En enero de 1930, el Diario de Costa Rica publicó 1701 anuncios ofreciendo los más diversos bienes y servicios, un promedio de 24,65 anuncios por día. De la totalidad, 927 (el 37.63\%) corresponden a medicamentos, como evidencia el Gráfico 1. Es una indudable mayoría que supera en mucho a todas las demás ofertas.

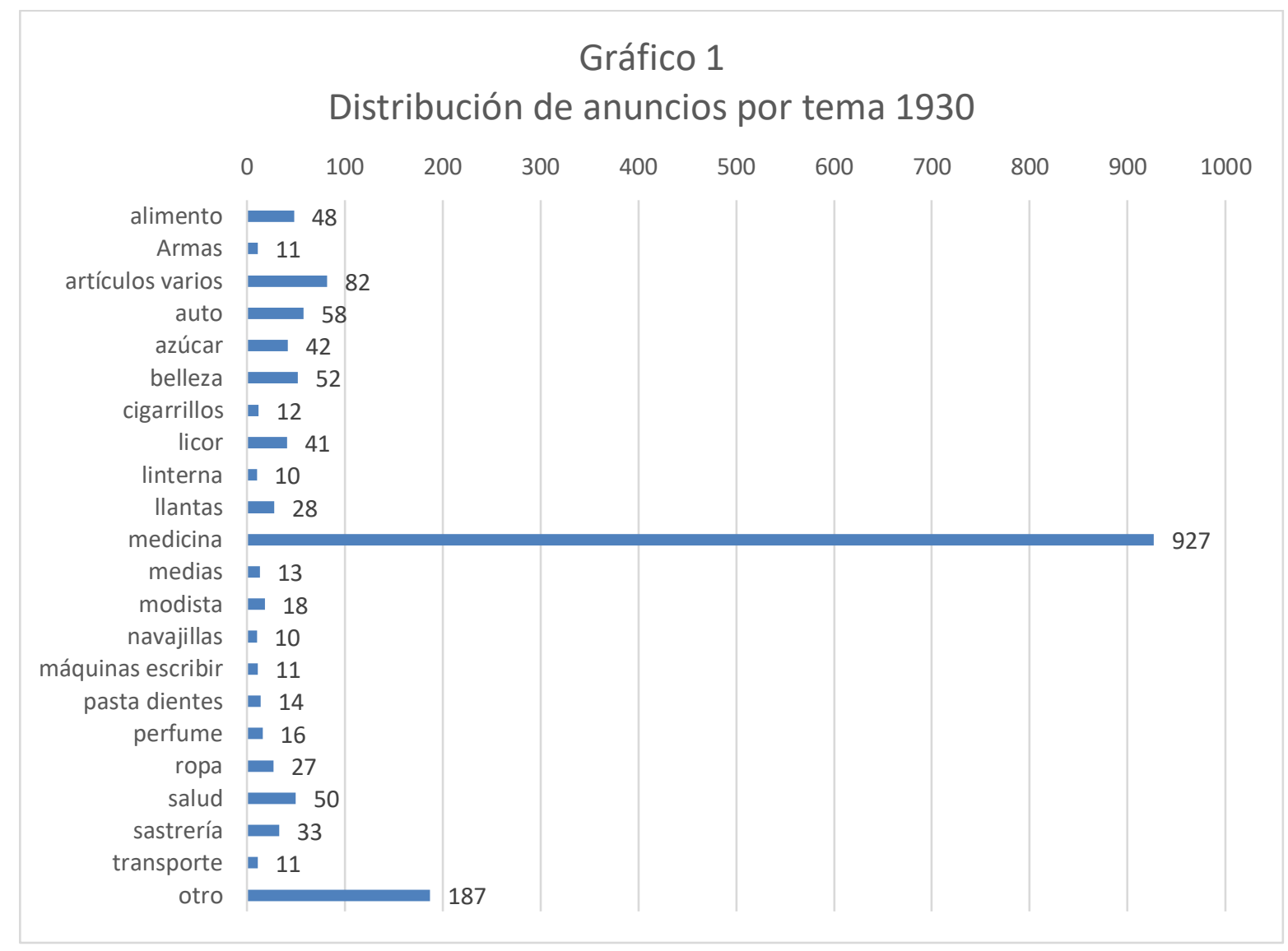

Fuente: Diario de Costa Rica, 1-1-1930 a 31-1-1930 
Los avisos comerciales ubicados en la categoría de belleza tienen como denominador común apelar a los cuidados personales. Se refieren fundamentalmente a productos que prometen hacer crecer los senos a las mujeres, mercancías para la limpieza dental o shampoo para el cabello, blanqueamiento de la dentadura, jabones que humectan la piel entre otros. Incluso, si se tomaban las píldoras Reuter con regularidad, tanto hombres como mujeres podían mantener su juventud (Diario de Costa Rica, 4-1-19, p. 8).

La cera mercolizada prometía un "Cutis más terso, Blanco, suave y Bello. Remueve las arrugas y restaura el matíz juvenil" (Diario de Costa Rica, 26-01-1930, p. 8). También la crema Bella Aurora además quitaba las pecas (Diario de Costa Rica, 9-3-1930, p.3). Ambas competían por abrirse espacio en el mercado josefino. Los salones de belleza proliferan en esos momentos igual que las academias que entrenaban a las mujeres en los cortes y teñido del cabello (Mora, 2017: 113 y 119).

Los productos ubicados en la categoría de salud ofrecen jabones medicinales, compuestos para convalecientes, pósimas para recuperar la vitalidad, alimentos que proporcionan energía, anteojos entre otros. Se trata de mercancías que no atacan una enfermedad específica.

Se venden bombillos en las ferreterías, pero también linternas y baterías.

En 1930, las mujeres y los hombres (sastres) que confeccionaban ropa eran artesanos habituales. Las telas llegaban a las principales tiendas josefinas procedentes del exterior y las modistas, cada una con más o menos clientela, asumían la hechura de los vestidos de moda que usaban las mujeres, según los dictados que exhibían las revistas, francesas, estadounidenses o inglesas que llegaban a las librerías. Por lo general, las costureras recibían inducción en la confección de ropa y la habilidad se desarrollaba con la práctica. Otras combinaban su destreza con enseñar a coser a otras mujeres, como lo anunciaba la modista Isaura de Caldera (Diario de Costa Rica, 4-1-1930, p. 10) en los primeros días de enero de 1930. Los sastres, por su parte, eran quienes atendían las necesidades de los hombres en el vestir y a juzgar por los anuncios, eran artesanos muy cotizados. A diferencia de las modistas, estos hombres promocionaban su tienda por el nombre de marca y no de su dueño como era común: la colombiana, El Pilón. Algunos hacían alusión a sus apellidos: R. A. Miranda, Biamonte y Rimolo.

Los autos y las llantas ocupan un lugar importante en la publicidad del periódico. La importación de automóviles había comenzado en la primera década el siglo XX (Quesada, 2008: 856), pero no será sino hasta después de 1920 que se evidencia un fuerte incremento. Se trataba de un producto de lujo, destinado a la diversión y al transporte privado, pero (p. 860) luego de 1930, ingresaron los autocamiones, con el propósito de transportar mercancías y personas. 
Aparejado a la importación de vehículos automotores, se amplió la compra de gasolina, ya utilizada para diversas actividades productivas desde hacía varias décadas, el asfalto y las Ilantas de caucho - Ilantas Seiberling, De Luxe, Oild Field-, que son frecuentemente anunciadas en los periódicos -. Estos productos, procedentes principalmente de Estados Unidos, fueron aumentando decididamente en el mercado. Surgieron los servicios de talleres de automóviles, como el Garage Ghisellini que en 1930 ofrecía un "servicio rápido de buenos carros". Godrich publicitaba su taller de vulcanización que contaba "con máquinas muy modernas" (Diario de Costa Rica, 18-2-1930, p. 2). Es evidente que la importación y uso de los automóviles dinamizó un espacio comercial que se diversificó según las necesidades que los automotores iban requiriendo.

La oferta de servicios era un tema permanente en los periódicos, aunque eran menos que los anuncios de productos -se publicaron 265 servicios y 1436 bienes-. Solo dos profesiones se promocionaban: los médicos y los abogados. Los artesanos especializados se daban a conocer a través de avisos comerciales: los sastres y modistas, que ya se han mencionado, los transportistas y los fotógrafos, constructores, intermediarios, cocineros y maestros de costura. Esta diversidad de anuncios evidencia el dinamismo social y económico que caracterizaba a Costa Rica en 1930.

A nivel formal, los anuncios no ocupaban un espacio determinado en las páginas de los periódicos. Variaban según la diagramación y la cantidad de anuncios. Parecen ser colocados donde quedaba espacio, no en un lugar permanente o estratégico.

No usaban fotografías, se apoyaban en dibujos de hombres, mujeres y envases, acompañados de letras que conformaban explicaciones, más o menos detalladas de las virtudes del producto, muchas veces en un lenguaje técnico empleado por una minoría de la población, especialmente cuando se trata de medicamentos.

\subsection{Los medicamentos}

Es evidente que los anuncios sobre medicamentos son, en mucho, superiores en número a todos los productos y servicios que se divulgaban en los periódicos. Este comportamiento se explica por el desarrollo de la industria farmaceútica, que estaba poniendo en práctica para entonces, una estrategia publicitaria con el objetivo de dar a conocer sus productos y sus cualidades, pero también es debido al accionar de especuladores y mentirosos que aprovechaban el espacio publicitario para ofrecer cremas, líquidos y pastillas que garantizaban falazmente, la cura de cualquier tipo de enfermedad.

Como se expone en el Gráfico 2, de los 927 anuncios que se analizaron a nivel textual e iconográfico, la mayoría de los productos ofrecidos prometen sanar o aliviar el resfrío. Efectivamente, los males respiratorios eran frecuentes en Costa Rica en la década de 
1930. La humedad, producto de las lluvias constantes y las condiciones no adecuadas de las viviendas, sobre todo en las zonas marginales, afectaban la salud de los habitantes. La frecuencia del padecimiento supone que la adquisición de medicamentos es permanente constituyéndose en un mercado en crecimiento.

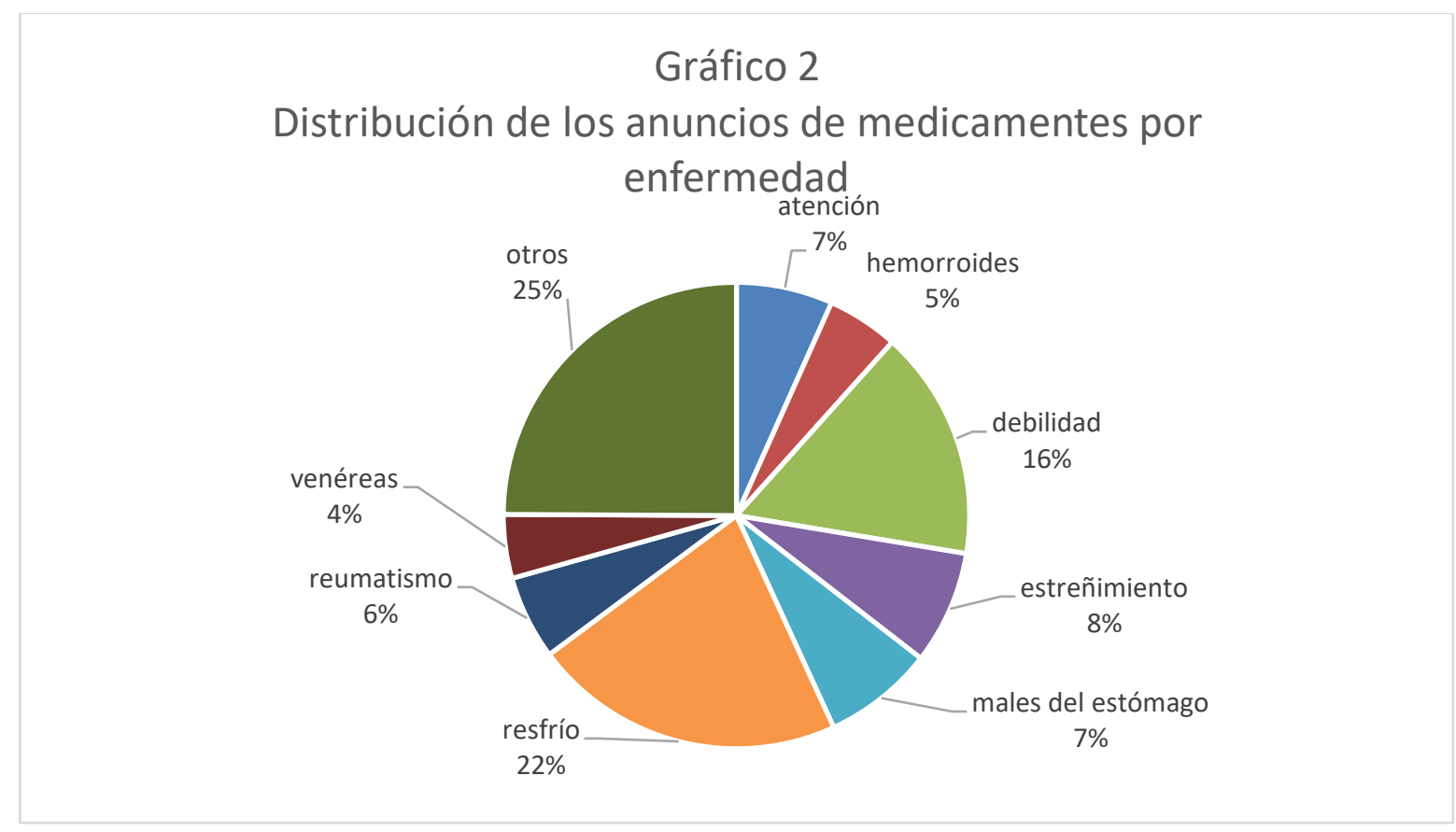

Fuente: Diario de Costa Rica, 1-1-1930 a 31-1-1930

No obstante, se confundían las enfermedades: el resfrío, la tos, el asma, la bronquitis, tuberculosis, entre otros eran considerado lo mismo, o al menos se combatía con el mismo remedio. El Kipsol eran píldoras que ingiriendo de 1 a 7 al día o una cada hora, "preserva y cura catarro, a la cabeza gripe tos" (Ilustración 1).

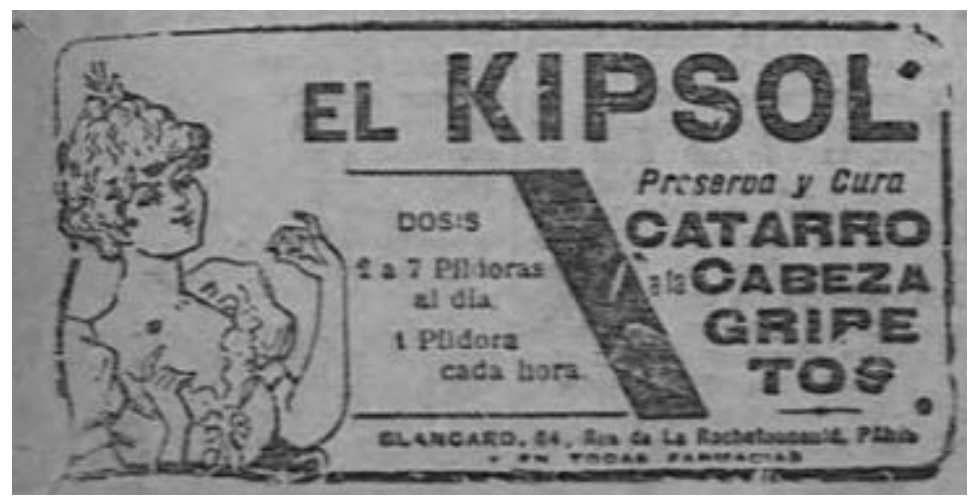

Ilustración 1: Diario de Costa Rica. 07-01-1930, p. 6 
El Bromo Quinina era un laxante que además eliminaba el resfrío (véase ilustración 2). La Quinina se identificaba "con la firma E.W. GROVE en la cajita", lo que le proporcionaba al producto el distintivo de calidad que significa ser producido fabricado fuera de Costa Rica. Las posibilidades de los productos de sanar varias enfermedades, muy diferentes entre ellas, resulta una estrategia muy frecuente en la publicidad de medicinas.

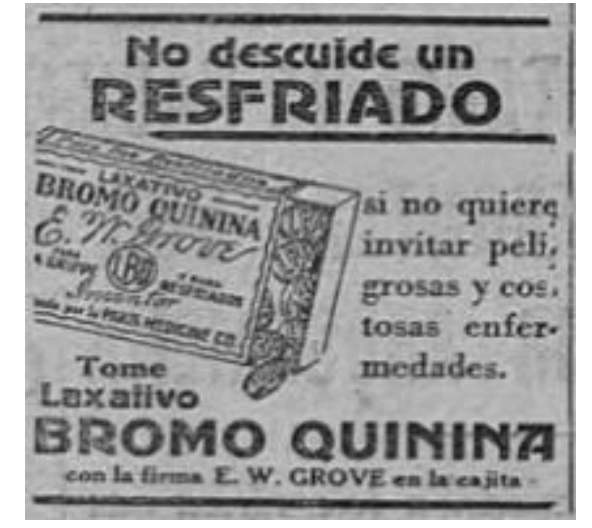

Ilustración 2: Diario de Costa Rica. 8-1-1930, p. 2

Pero más novedoso aun y más efectivo, el vaporizador Vicks prometía anular "toda afección catarral". Explicaba detalladamente en el anuncio que "la mayoría de las afecciones catarrales comienzan por una inflamación de la delicada membrana de las vías respiratorias a causa, generalmente, de microbios que se han aspirado. La forma más rápida de atacar estos microbios es por medio de vapores medicinales que también puedan aspirarse." Su aplicación era simple, se frotaba en el pecho antes de acostarse y eso permitía que los vapores aflojaran la flema, despejar la nariz tapada, aliviar el dolor de garganta "y permiten al enfermo dormir en calma...". Pero no solo lograban curar las afecciones respiratorias, sino que dadas las "propiedades curativas, antisépticas de Vicks hacen que sea también una aplicación excelente para afecciones superficiales, tales como cortaduras y contusiones. Para los dolores de cabeza que provienen de catarros 0 fatiga, trae pronto alivio frotando en la frente y las sienes" (véase ilustración 3). Esta narración pormenorizada tenía como objetivo evidenciar el conocimiento de los males y con ello, dar respaldo verosímil al producto que se ofrece y asegurar la efectividad. 


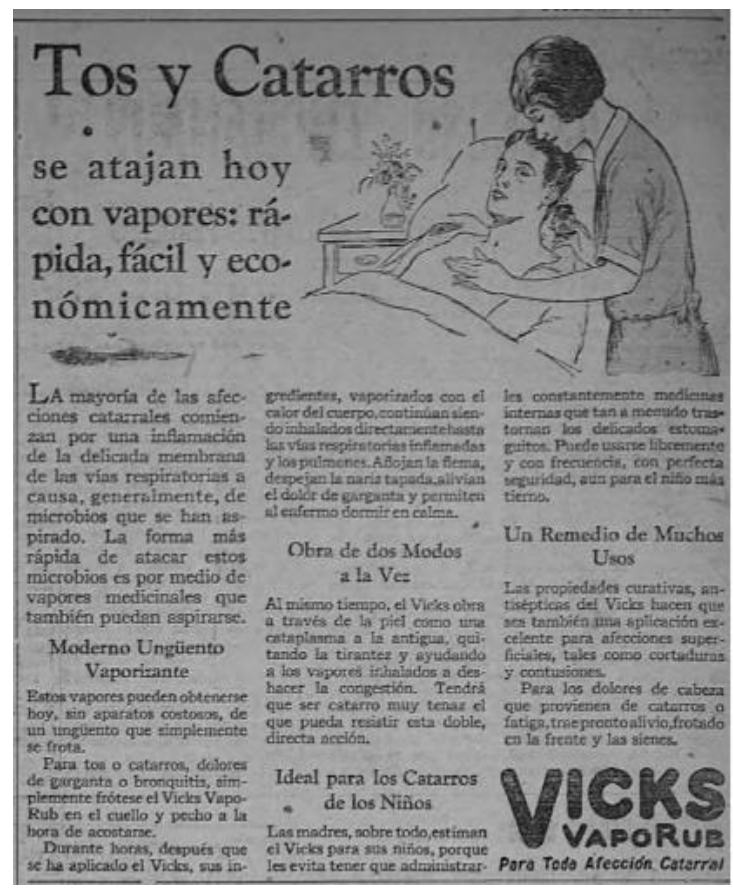

Ilustración 3: Diario de Costa Rica. 7-1-1930, p.10

El uso de los vapores para curar una constipación también lo ofrecía "Mentholatum", producto que compite con Vicks. Además de contar con un logo claramente definido, la estrategia publicitaria consiste en apelar al interlocutor de manera directa y clara: “¿Por qué sufrir? Si está Ud. sufriendo de catarro y se encuentra sola y aislada (en una clara alusión a la mujer como público meta), es por su propia culpa, pues hoy todo esto puede evitarse si desde los primeros síntomas se aplica Mentholatum en las fosas nasales, garganta y pecho, e inhala los vapores que se desprenden poniéndolo en una tasa con agua hirviendo. (Igual que su competidor, Mentholatum) no tiene rival para golpes, contusiones, quemadoras, cortadas, etc. Exija siempre el legítimo en sus envases originales, tubos, tarros y latas" mostrando y destacando de esa manera, las diferentes presentaciones que ofrecía el mismo producto (Diario de Costa Rica, 4-1-1930, p.2).

Mentholatum era producido desde 1889 por la empresa estadounidense The Mentholatum Company inc. Se trata de un producto farmacéutico que no tiene prescripción médica e igual que el Vicks Vapo Rub no es inofensivo (Ortega, 2012: 1) El Mentholatun es un compuesto que contiene alcanfor, eucalipto, mentol, aceites de trementina, nuez moscada, thuja occidentalis y vaselina. La aplicación en niños menores de dos años, tanto este como el Vick, estimulan "la inflamación bronquial y secreción mucosa, lo que podría llevar al bebé a una insuficiencia respiratoria". Ambos productos se popularizaron y se internacionalizaron tras su uso en la pandemia de 1918. Ya para 1930 ambos destacaban en sus anuncios la grafía que identifica el producto. 
En muchos casos posiblemente los enfermos padecían tuberculosis, una afección muy frecuente en Costa Rica en esos años. Es producida por una bacteria que sin tratamiento, llevaba a la muerte. "El surgimiento de sanatorios, la implementación de antibióticos fueron elementos fundamentales en la lucha antituberculosa" (Cartes, 2013: 150). A principios del siglo XX iniciaron en Francia las investigaciones para la elaboración de una vacuna antituberculosa. Los primeros ensayos en personas adultas e infantes iniciaron en 1921 pero su eficacia no quedó demostrada (p. 148). Sin embargo, en los anuncios publicados por el Diario de Costa Rica invitando a las personas a vacunarse, afirmaban, demostrándolo con "estadísticas" que la vacuna era una eficiente cura, de manera tal que la inoculación era expuesta como un medicamento más y no como una preparación destinada a generar inmunidad contra un mal pues estimula la producción de anticuerpos (véase ilustración 4).

Los ensayos en busca de solución a la enfermedad condujeron a probar con distintas sustancias a finales del siglo XIX y principios del XX: tuberculina, colorantes, sales de arsénico, aceite de hígado de bacalao, sales de cobre, entre otros. Los resultados fueron desalentadores (Vega, 2000: 188-189).

En Costa Rica la tisis o tuberculosis "fue causante de un alto nivel de mortalidad entre la población, lo que requirió un combate decidido encabezado por el sanitarista Dr. Carlos Durán Cartín, quien siendo diputado de la República logra los fondos suficientes para adquirir los terrenos que albergarían el Sanatorio Carlos Durán Cartín" (Araya, 2013: 1). El hospital se ubicó en una zona de clima frío, al que estaban expuestos los pacientes como parte de su tratamiento y además recibían alimentación abundante y variada, tal y como se consideraba en las prestigiosas escuelas de medicina a nivel mundial. Lo cierto es que el internamiento de los enfermos en ese recinto, condujo al aislamiento de los dolientes, de manera tal que se evitó el contagio y con ello disminuyó la cantidad de infectados.

La vacuna que se promovía era marca Friedmann, que refería al profesor del instituto de investigaciones sobre tuberculosis de la Universidad de Berlín. En efecto, el Dr. Friedmann (1933) había logrado desarrollar varias investigaciones tendientes a combatir la enfermedad y aunque sus avances fueron significativos, no lograron atacar al mal, resultado que se conseguiría hasta la década siguiente. Lo interesante es que vendía el resultado de sus hallazgos a compañías farmacéuticas que las colocaban en mercados de todo el mundo, además publicó un manual para ser usado por quienes lo consideraran, donde detallaba no solo el compuesto de la vacuna, sino también el resumen de sus hallazgos (véase ilustración 5). 


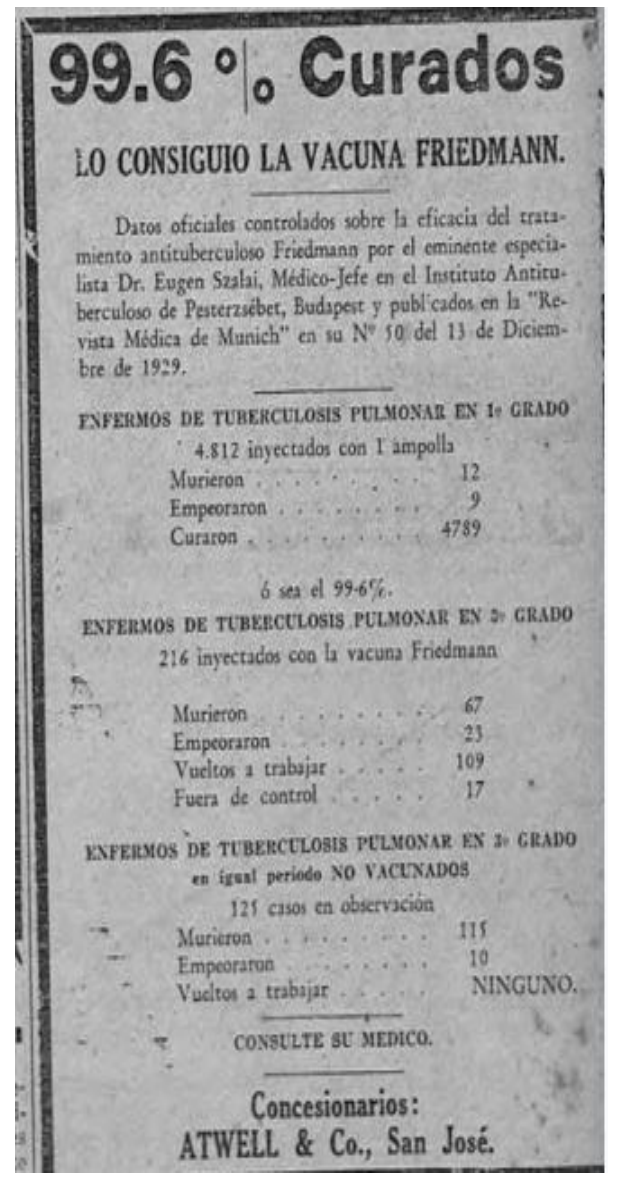

Ilustración 4: Diario de Costa Rica. 12-01-1930, p. 3.

Entre tanto, la debilidad, pérdida de energía, decaimiento y cansancio, eran condiciones aprovechadas por los comerciantes para ofrecer fórmulas "mágicas" capaces de combatir esos síntomas. Los medicamentos más frecuentes eran: píldoras Foster, Musculosine, Emulsión Scott, Quaker Oats, Simila Similibus Curantur, Fostatina Falieres, Goce, Sal Hepática, Terapéutica Delbiase, Vino St- Raphael y Jarabe de Dusart, Muscolosine Byla. Las primeras ayudan también a los riñones pues, según indican en su anuncio, el dolor de cintura y el vértigo que impide el movimiento, son indicadores de que hay problemas renales. Los anunciantes reconocen que el "debilitamiento" puede ser producto de diversas causas.

Musculosine era el resultado de la combinación de distintos ingredientes más la sangre de buey "cruda" lo que significaba que quien consumía el brebaje, adquiría la fuerza de ese animal. Entre tanto Simila Similibus Curantur, se refiere al uso de homeopatía para atacar la debilidad corporal o mental (Diario de Costa Rica, 8-1-1930, p. 4). 


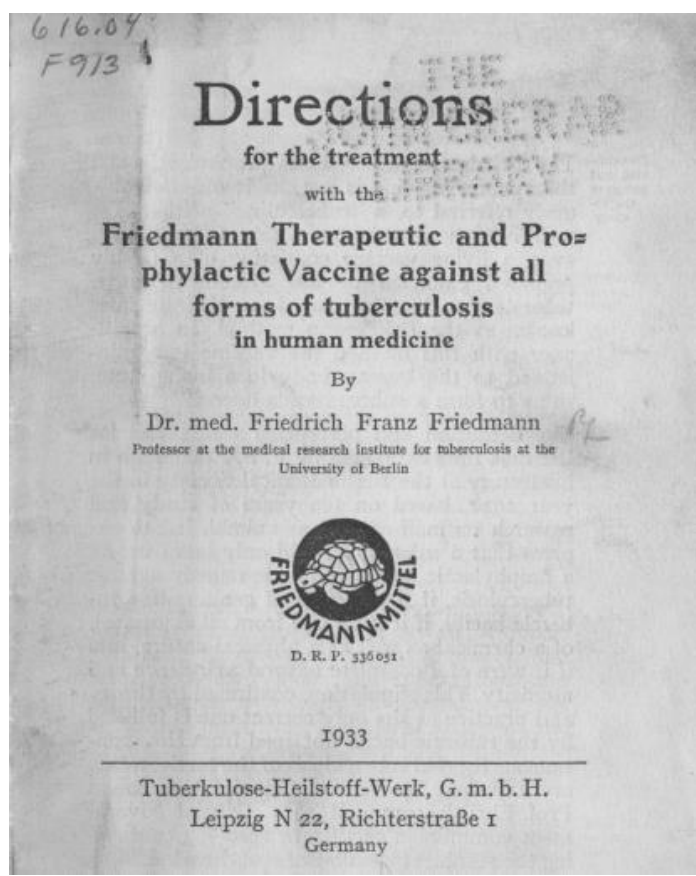

Ilustración 5. Fuente: http://storage.lib.uchicago.edu/pres/2014/pres2014-0098.pdf

Toda enfermedad que se manifestaba con los síntomas de "debilidad" o "cansancio" se catalogaba únicamente como "agotamiento", por tanto no había más diagnóstico y fuese cual fuere la enfermedad que aquejaba el paciente, era tratado con los mismos productos reconstituyentes.

Por la cantidad de anuncios, se supone que el "debilitamiento" era un mal frecuente en la población. Para entonces la investigación médica había descubierto un padecimiento denominado anquilostomiasis, una infección intestinal causada por parásitos y ampliamente diseminada por el mundo y en particular en las zonas tropicales húmedas como Costa Rica. Desde principios del siglo XX (1907), el gobierno financió un programa para combatir la enfermedad dirigido a toda la población sin distingo de etnia o condición social. En 1914 se puso en marcha el proyecto de la Fundación Rockefeller tendiente a erradicar el mal (Palmer, 2009: 2).

Este parásito provoca infección en el intestino que se manifiesta con erupciones cutáneas pruriginosa donde la larva atraviesa la piel. Pueden aparecer fiebre, tos, sibilancias o dolor abdominal, pérdida de apetito y diarrea. Las infecciones graves causan pérdida de sangre y anemia, como se señaló, que a veces es lo suficientemente grave como para provocar cansancio, y en algunas ocasiones, insuficiencia cardíaca e hinchazón generalizada entre otras manifestaciones e incluso anemia que postraba a quien la poseía y podía incluso causar su muerte. Era particularmente vulnerable la gente que no usaba zapatos pues el parásito se introduce por el pie. A principios de siglo, una mayoría caminaba descalzo. 
La irresponsabilidad de los anunciantes conduce a prometer a la población la cura de un mal que estaba matando a las personas. Los accesos de tos, podrían ser parte del mal de la anquilostomiasis y sin embargo los especuladores aseveraban que era un resfrío y ofrecían y prometían remediarlo.

Hubo quienes tuvieron la osadía de ofrecer "DELBIASE" comprimidos de sales que no solo aumentaba la resistencia contra la fatiga, facultaba la actividad cerebral, regularizaba las funciones intestinales, combatía las enfermedades del hígado, favorece la asimilación de los alimentos y hacía desaparecer acnés, pruritos, eczemas verrugas y otras afecciones de la piel, (sino que) por su uso regular eliminaba la presencia del CANCER y de las afecciones precancerosas (Diario de Costa Rica, 8-1-30, p. 6).

La almorrana, que es una inflamación varicosa en la parte exterior del ano y en la parte final del intestino, mejor conocidas como hemorroides (Peuthi, 2019: 1), se produce generalmente por el esfuerzo realizado constantemente por personas que sufren estreñimiento. Es posible que la alimentación basada en granos y verduras (harinas) y la falta de hidratación, no favoreciera la evacuación frecuente en buena parte de la población. Con la pomada Midy, aseguran sus expositores, las hemorroides "se alivian siempre y se curan generalmente con la pomada Midy" (véase ilustración 6).

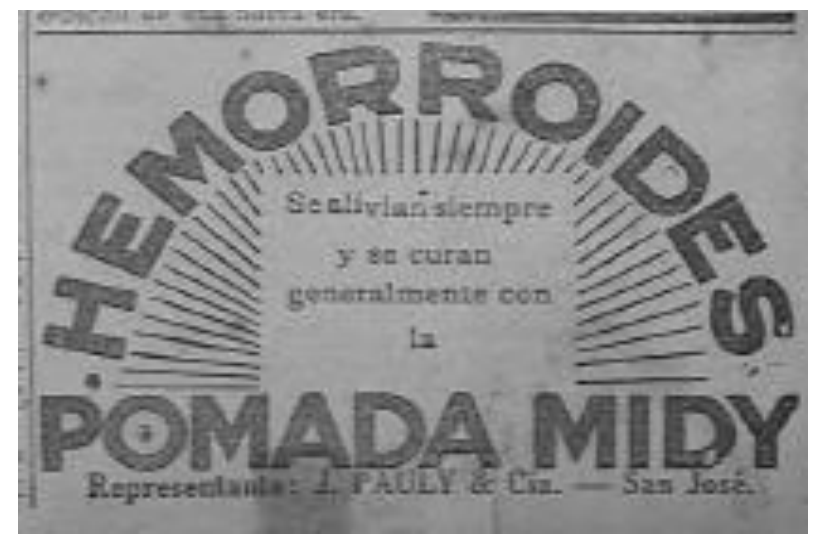

Ilustración 6: Diario de Costa Rica. 05-01-1930, p. 12.

Pero tanto para el estreñimiento como para la diarrea, se ofrece el “Elixer estomacal de Saiz de Carlos" (véase ilustración 7). O sea, un mismo producto sanaba males opuestos. Este balsam, aseveran los anunciantes, es recetado por los médicos "de las cinco partes del mundo porque quita el dolor de estómago, las acedias, la dispepsia, los vómitos, las diarreas en niños y adultos que a veces, alternan con estreñimiento, la dilatación y ulcera del estómago; tonifica, ayuda a las digestiones y abre el apetito siendo utilísimo su uso para todas las molestias del estómago e intestinos". Se trata de un remedio que se aplica igual a niños de todas las edades, y a adultos. 
Este elixer estomacal Saiz de Carlos compite con las píldoras Reuter pues "además de ser un laxante eficaz, educa el intestino a su movimiento diario sin causar dolor ni inflamación...", estimula las funciones del hígado.

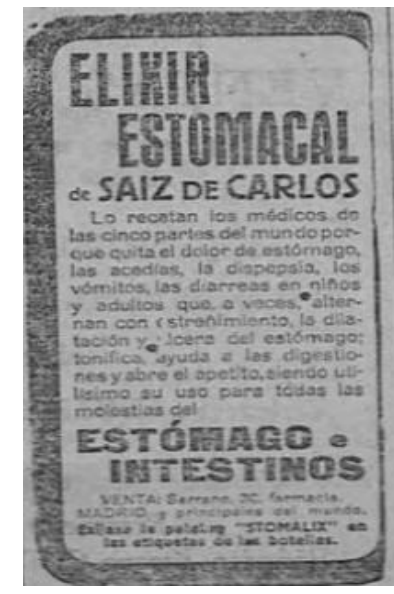

Ilustración 7: Diario de Costa Rica. 07-01-1930, p. 7.

Incluso para los niños ofrecían Laxol, un laxante que debía ser administrado diariamente a los pequeños para mantener sus intestinos limpios y activos.

Por otra parte, las medicinas contra las enfermedades venéreas, como la gonorrea, eran con alguna frecuencia, anunciadas en los periódicos. En una sociedad que se ha supuesto conservadora, la presencia de esa enfermedad debió ser ocultada por quienes la padecían. Como ocurre con otros medicamentos, hay algunos que aseveran curar la gonorrea y lo hacen a través de la "vacuna inava" que era vendida por el licenciado Rogelio Fonseca, en su tienda ubicada "200 varas al norte de El Carmen" -en el corazón de la ciudad capital-. Este anuncio en particular recurre a una estrategia de persuasión que se utiliza desde finales del siglo XIX: respaldar las afirmaciones propagandística con testimonios, de modo tal que los usuarios potenciales tienen como sustento las pruebas que proporcionan quienes emiten los testimonios. En algunos casos, se mencionan los nombres de los testigos, en otras, como en el caso de este anuncio de la vacuna inava, solo se advierte que "gran número de testimonios demuestran el éxito obtenido" (Diario de Costa Rica, 31-1-1930, p. 2).

El elixir denominado "Específico de Leonardi" (prometía cura para) la blenorragia y la gonorrea y flujos recientes o crónicos en tan solo 3 o 5 días (Diario de Costa Rica, 12-11930, p. 2).

Este remedio compite con la marca Heidisan, de origen alemán, que para entonces "había reportado grandes beneficios para la humanidad". Era un líquido inofensivo, económico y con resultados seguros y no requiere cambio en el modo de vivir. Los pacientes podían encontrar este "medicamento" en droguerías y boticas. Esta distinción 
significaba que en la primera, los dependientes preparan las pócimas en el acto y en las boticas, se vendían preferencialmente, pociones ya preparadas (Diario de Costa Rica, 31-1-1930, p. 2).

Para 1930, hubo médicos promocionándose como especialistas en enfermedades venéreas y del útero. El Doctor Padilla por ejemplo, era, según su anuncio, especialista en esas áreas. Su consultorio estaba ubicado en la esquina opuesta de la botica francesa (Diario de Costa Rica, 10-01-1930, p.8).

Sexocrin era un producto que proporcionaba a los hombres energía sexual, lo ayudaba a "procrear en la vida, salud, poder y energía". Según advertían en la propaganda, "produce emoción de bienestar y sosiego dando nueva vida a los órganos agotados o débiles... VIDA PROGRESIVA es un volumen que explica y da consejos para tener hijos sanos: como obtener poder mental y del sexo, siendo una gran inspiración a todo hombre..." (Diario de Costa Rica, 19-02-1930, p.8).

El reumatismo y los problemas hepáticos también tenían cura en pocos días según los anunciantes. El ungüento Baume Bengué aseveraba ser "curación radical de gota, reumatismo y neuralgias" (Diario de Costa Rica, 2-2-1930, p. 3).

El darle un nombre poco común, que además se puede relacionar con nombres afrancesados o en inglés, le da al medicamento un respaldo de calidad. Incluso, los médicos que ofrecen sus servicios, como el Doctor A. Acosta Guzmán, destaca que además de ser médico y cirujano y ginecólogo, obstetra y especialista en el aparato digestivo, estudió en Alemania, lo que significa, en el imaginario colectivo, que tiene conocimientos de avanzada.

El origen de la mercancía se destaca como un signo de calidad del producto. Esta estrategia estaba acorde con la noción de progreso del proyecto liberal que implicaba una asociación con lo urbano, lo europeizante y laico. Hacia 1930, las ideas iluministas de la cultura francesa, por ejemplo, comparten con el modelo estadounidense (Cuevas, 2012: 1).

Los problemas en las vías urinarias, las impurezas de la sangre y la debilidad, se curaban con las grageas del Dr. Soivre. Cuando mencionaba las vías urinarias se refería a la "Blemorragia (purgaciones) en todas sus manifestaciones. Uretris, orquitis, ciatitis, gota militar, etc. Del hombre y vulvitis, vaginales, metritis, uretritis, cialitis, ... flujos de la mujer se curan por sí solo, con los cachets del Dr. Soivre, sin necesidad de inyecciones, lavados ni aplicación de sondas o bujías, etc., tan peligrosos siempre y sin que nadie se entere de la enfermedad, vendiéndose a \5.50 la cajita". 
Las mismas grágeas combatían las "impurezas de la sangre: sífilis (avariosis) eczemas, herpes, ulceras varicosas (Ilagas de las piernas), erupciones escrofulosas, eritemas, acné, urticaria, etc. Enfermedades que tienen por causas humores, vicios o infecciones de la sangre se curan pronto con las píldoras depurativas del Dr. Soivre, que es la medicación depurativa ideal y perfecta porque actúan regenerando la sangre, la renuevan, aumentan todas las energías del organismo y fomentan la salud resolviendo en breve tiempo todas las úlceras, llagas, granos ... supuración de las mucosas, caída del cabello, inflamaciones den general, etc., quedando la piel limpia y regenerada no dejando en el organismo huellas del pasado..." (Diario de Costa Rica, 20-01-1930, p. 7).

Había medicinas que aseguraban ser capaces de curar la ceguera, por ejemplo la loción Leonardi, prometía refrescar, curar y fortalecer los ojos débiles y además, aliviar casi todos los males de los ojos. No explica cómo se administra al doliente (Diario de Costa Rica, 10-01-1930, p. 7).

Las pastillas Pilules Galton eran recomendadas contra la obesidad, pues adelgazaban al usuario de seguro en pocas semanas (Diario de Costa Rica, 11-1-1930, p. 4).

\subsection{Tácticas publicitarias del Diario de Costa Rica}

El Diario de Costa Rica contaba para 1930 con un departamento de publicidad desde el cual diseñaban un plan de acción para fomentar la venta de un determinado producto.

De hecho, ofrecían al público "nuestro servicio exclusivo de ilustraciones con una importante Compañía de Expertos en el Ramo del Anuncio (que) nos permite ofrecerles muchas ideas sugestivas para hacer un buen anuncio. Este servicio lo ofrecemos completamente gratis a nuestros clientes. Nuestro Representante don Roberto J. Thompson tendrá mucho gusto en darles informes" (Diario de Costa Rica, 5-1-1930, p.9).

Ofrecían también el servicio exclusivo de ilustraciones "libre para quien lo solicita" (Diario de Costa Rica, 7-1-1930, p. 9) y asimismo "Nuestro Diario tiene los derechos exclusivos de una importante compañía Americana de Expertos en el Ramo de Anuncios en este país. Esto nos permite adquirir centenares de ilustraciones apropiadas para cada fin inimaginable, que tienen en nuestros archivos la matriz correspondiente (Diario de Costa Rica, 9-1-1930, p.9).

Posiblemente de ese conjunto de imágenes, en dibujos, pues no se usaban entonces fotografías, elegían las que acompañaban el anuncio de los medicamentos, que además abundaban en letras y explicaciones, que correspondían a "esquemas preparados por profesionales" que se adaptaban a los requerimientos de lo anunciado (Diario de Costa Rica, 10-1-1930, p. 9) 
Los anuncios publicitarios del Diario de Costa Rica, practicaban una serie de estrategias persuasivas: uso de logos, uso de grafías, destaque de virtudes del artículo como la experiencia, la calidad, la efectividad del producto. Una característica evidente es que apela a los lectores como interlocutores que dominan el mismo código de significación y por ello, se comprenden. En otros términos, se apela al potencial comprador en su mismo lenguaje, donde identifica su entorno, sus necesidades, sus arraigos, sus tradiciones, sus intereses... Las descripciones de los anuncios son simples y directas: limpia la sangre, ataca la debilidad o los nervios, los enflaquecimientos, los escalofríos, la tos, los males el estómago, etc.

Seducen al público para promover la demanda a través de estrategias diversas como exponer las ventajas del producto frente a la competencia, pero también utiliza estrategias de contenido, pues estimula la compra a través de intensificar las motivaciones y argumentos de la compra en el receptor. Los mensajes, en una minoría, consisten en una idea atractiva, fácil de recordar, asociada a los atributos positivos.

Algunos productos tenían sus propias marcas y por ello su grafía y logo particular que identificaba claramente al producto. Emulsión Scott, por ejemplo con la imagen del pescador con el bacalao al hombro, mantiene incluso el lugar donde se ubica la imagen (esquina inferior izquierda), y la misma grafía con el nombre, como se expone en la ilustración 8.
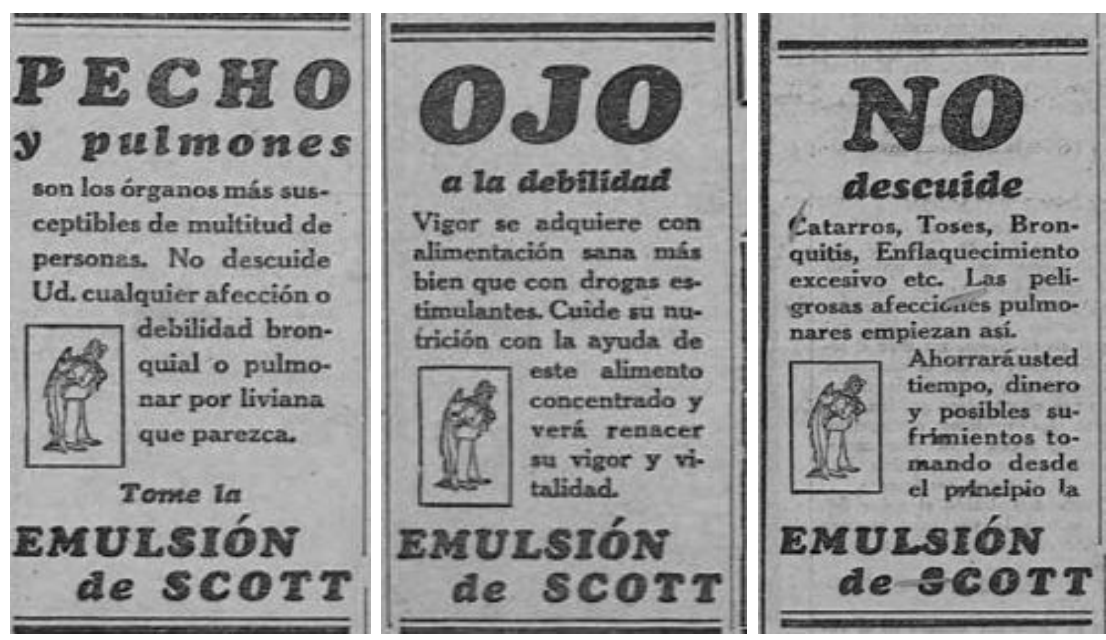

Ilustración 8: Diario de Costa Rica. 7-1-1930, p. 11. 9-1-1930, p. 8 y 7-1-1930, p. 6

\subsection{Control de la publicidad}

Ante la inescrupulosa publicidad de productos medicinales, los gobernantes reaccionan quince años después del periodo estudiado, en 1945. En primer término apelaban a la obligatoriedad de emplear un lenguaje sencillo y discreto, pues el uso de un vocabulario 
técnico llamaba a la confusión o a interpretar incorrectamente el mensaje del anuncio, situación que podría tener efectos nefastos.

Insistía la legislación, además, que el anuncio tenía que estar "en un todo ajustado a la verdad y a la moral". Se prohibía abusar "de la credulidad de la gente (por tanto, no se permitía concederle) al producto propiedades distintas a aquéllas que por la composición de su fórmula están indicadas". En otros términos, obligaba a los anunciantes ser honestos

"Para hacer efectiva e invariable la seriedad y discreción del lenguaje que debe aplicarse en la redacción de los anuncios, y para que los interesados conozcan el rumbo a seguir en este particular, no se permitirá la publicación o difusión de anuncios en cuya redacción entren términos o frases como las siguientes: "cura", "curativo", "sana", "sanativo", "seguro", "mágico", "mágicamente”, "el mejor", "el más activo, "el más", "el insuperable", "el insustituible", "el maravilloso", "el milagroso"; los que se refieran a fórmulas secretas o a descubrimientos de médicos o químicos y a todas las demás frases o palabras que signifiquen acción ruidosa, poco seria o condición preferente para el producto que se anuncia" (Colección de leyes y decretos, 1945: 160).

Los legisladores combaten de esta manera la oferta de los productos milagro que ponían en peligro la vida de la población. La efectividad de esta ley aun está por estudiarse.

\section{Conclusiones}

¿Por qué se ofrecen medicamentos o productos milagro que superan en número los anuncios sobre otros bienes y servicios? Es posible que los productos que aseguraban bienestar -cura segura o alivio inmediato para una enfermedad-, tenían garantizada la venta. Aunque los anunciantes no evidencian un estudio de mercado, lo cierto es que conocían los padecimientos más frecuentes en la población y se aprovechaban de esa información para colocar en el mercado el remedio o el producto que cura al doliente.

Para el periódico constituía un ingreso nada despreciable que le permitía seguir circulando, sin importarles las falacias sobre las cuales se sustentaba el aviso comercial.

La presencia de las enfermedades garantiza la posibilidad de venta de los productos. Se aprovechan del dolor ajeno y del temor a la muerte y a la enfermedad para vender el elixir que en muchos casos, pudo empeorar al enfermo e incluso conducirlo a la muerte.

Al estudiar los anuncios sobre medicamentos y contrastarlo con otras fuentes, se evidencia la existencia frecuente en Costa Rica en el mes de enero de 1930 de problemas respiratorios, digestivos, anemias, enfermedades reumáticas y vénereas. Estas últimas 
eran tratadas por médicos supuestamente especialistas que garantizaba no solo la cura sino también la discrecionalidad, una condición fundamental en el discurso moral de la época.

Por otra parte, al existir un mercado garantizado para los medicamentos, su publicidad está dirigida a mantenerlo y a ampliarlo, no a colocar el producto que ya de por sí tiene demandantes.

Ciertamente muchos de los anunciantes eran personas inescrupulosas, desconocedores de la materia aunque aseveraran que tenían el respaldo de profesionales de la salud (médicos, farmacéuticos, químicos, etc.). De igual manera se apoyaban en expertos extranjeros, procedentes de las principales potencias del momento: Estados Unidos, Francia, Inglaterra y Alemania.

Aunque el anuncio no dice qué o quiénes lo crearon, lo cierto es que en Costa Rica ya había, desde la década de 1920, agencias de publicidad cuyos integrantes aprendieron en la práctica el oficio de publicista. Incluso el Diario de Costa Rica tenía su propio departamento de publicidad y se encargaba desde la concepción de la idea hasta el diseño total incluyendo la imagen. No es posible saber cuántos de los anuncios que publicaban eran elaborados por ese departamento, pero algunos productos evidentemente tenían su propio cliché destacando su logo y/o su grafía como Emulsión Scott, Sal Hepática, Vicks Ba poru, entre otros.

Lo cierto es que es evidente la irresponsabilidad e inescrupulosa actitud de los anunciantes y la falta de control de las autoridades y el beneplácito de los responsables de los impresos.

\section{Referencias bibliográficas}

Agencia de diseño de empaque. Disponible en Internet (4-5-2020): http://www.brandwatch.com.mx/branding\#branding

ARAYA INCERA, M. (2013): "Datos para la historia de Costa Rica. Rescate de valores históricos", en Revista Médica de Costa Rica y Centroamérica, vol. 70, no608, pp. 743-745. Disponible en Internet (7-01-2020): https://www.binasss.sa.cr/revistas/rmcc/608/art30.pdf

BARBOZA, M. (2011): "Publicidad e identidades. La publicidad de bebidas alcohólicas en Costa Rica (1950-1959)", en Reflexiones, vol. 90, no 2, pp. 37-51. Disponible en Internet (2-5-2020): https://revistas.ucr.ac.cr/index.php/reflexiones/article/view/1459/32376 
BARRANTES OBANDO, R. (2018): "Modernidad y ocio: la publicidad de radios, consolas y televisores en la prensa costarricense (1950-1970)", en Rev. Ciencias Sociales, no 159, pp. 29-41. Disponible en Internet (4-5-2020): https://www.revistacienciassociales.ucr.ac.cr/html/02-BARRANTES/02BARRANTES.html

CARTES PARRA JC. (2013): "Breve historia de la tuberculosis". Revista médica de Costa Rica y Centroamérica. Disponible en Internet (7-01-2020): https://www.medigraphic.com/pdfs/revmedcoscen/rmc-2013/rmc131z.pdf

Colección de Leyes y Decretos de Costa Rica. (1945): 60.

CUEVAS, R. (2012): La cultura en Costa Rica, un permanente en construcción._Disponible en Internet

(10-01-2020) https://www.repositorio.una.ac.cr/bitstream/handle/11056/2364/recurso_462.p df? sequence $=1 \&$ isAllowed $=y$

DARNTON, R. (1987): La matanza de gatos y otros episodios de la historia cultural francesa, México, Fondo de Cultura económico.

FERNANDEZ POYATOS, M.D. (2011): "La publicidad de salud en la prensa ilustrada de finales del siglo XIX" en Questiones Publicitarias, VOL1, No. 16, 108-124. IS. Disponible en Internet (29-04-2020): https://www.questionespublicitarias.es

FRIEDMANN, F. (1933): Directions for the tratment with the Friedmann Therapeutic an Prophylactic Vaccine against all forms of tuberculosis in human medicine. Tuberkulose-Heilstoff-Werk, G.M.b.H. Leipzig N 22, Richterstrase I. Germany.

LAGUNA, A. (2018): Salud, sexo y electricidad. Los inicios de la publicidad de masas. España, Ediciones de la Universidad de Castilla-La Mancha.

MARIN, J. (1995): “De curanderos a médicos. Una aproximación a la historia social de la medicina en Costa Rica: 1800-1949” en Revista de Historia, no32, 1995, pp. 65108.

MIGUÉLES MARTÍNEZ, M. (2006). Validez y confiabilidad en la metodología cualitativa. Paradígma, 27(2), 07-33. Disponible en Internet (2-5-2020): http://ve.scielo.org/scielo.php?script=sci_arttext\&pid=S1011$22512006000200002 \& \operatorname{lng}=e s \&$ tlng=es.

MORA CARVAJAL, V. (2017): "La publicidad de productos de belleza femenina en Costa Rica (1900-1930)", en Cuadernos Intercambio sobre Centroamérica y el Caribe, vol. 14, no1, pp. 112-144. Disponible en (30-4-2020): https://dialnet.unirioja.es/servlet/articulo?codigo=5922107 
ORTEGA, R. (2012): Cuidado, el Vicks VapoRub y el Mentholatum no son inofensivos. International Press. Disponible en Internet (7-01-2020): http://internationalpress.jp/2012/06/09/cuidado-el-vicks-vaporub-y-elmentholatum-no-son-inofensivos/

PALMER, S. (2009): Cansancio y Nación: el combate precoz de los salubristas costarricenses contra la anquilostomiasis. Universidad Nacional de Lanús, Buenos Aires. Disponible en Internet (7-01-2020): https://www.scielosp.org/article/scol/2009.v5n3/403-412/

PALMER, S. (2005): From Popular Medicina to Medical Populsm. Doctors, Healers and Public Power in Costa Rica, 1800-1940. Durham, NC: Duke University Press.

PEUTHI, S. (2019): Hemorroides. Disponible en Internet (7-01-2020): https://www.mayoclinic.org/es-es/diseases-conditions/hemorrhoids/symptomscauses/syc-20360268

QUESADA, A. (2008): “Los primeros automóviles de Costa Rica: el impacto en las importaciones, la legislación y la publicidad (1907-1930)". Diálogos Revista Electrónica de Historia. Número especial 2008. Disponible en Internet (7-01-2020): http://historia.fcs.ucr.ac.cr/dialogos.htm

Sistema Nacional de Bibliotecas, SINABI. Disponible en Internet (1-5-2020): http://www.sinabi.go.cr/biblioteca\%20digital/periodicos/Diario\%20de\%20Costa \%20Rica.aspx\#.XqxhnBPOk8Y

SÁENZ, C, et. al. (1955): Clínica y terapéutica de la anquilostomiasis y de la tricocefalosis infantil en Revista Biología Tropical 3(2), 1955, pp. 135-160.

VEGA JIMENEZ, P. (1992). “De la banca al sofá. La diversificación de los patrones de consumo en Costa Rica (1857-1861)", en Molina, I y Palmer, S. (editories), Héroes al gusto y libros de moda. San José, Editorial Porvenir, pp. 109-136.

VEGA JIMENEZ, P. (1995): De la imprenta al periódico. Los inicios de la comunicación impresa en Costa Rica, 1821-1850. San José, Editorial Porvenir.

VEGA JIMEMEZ. P. (2000). "La comercialización de la salud y la muerte al finalizar el siglo XIX en Costa Rica”, en Molina, I y Enriquez, F. (editores), Fin de siglo XIX e Identidad Nacional en México y Centroamérica. Alajuela, Museo histórico cultural Juan Santamaría.

VEGA JIMENEZ, P. (2008): “Estrategias publicitarias en Costa Rica (1900-1930)", en Pensar la Publicidad, vol. II, no 1, pp. 45-78. Disponible en Internet (3-5-2020): https://revistas.ucm.es/index.php/PEPU/article/view/PEPU0808120045A/15524 
VEGA JIMÉNEZ, P. (2012): "Estrategias publicitarias en tiempos de crisis (publicidad en la prensa costarricense 1931-1932)", en Reflexiones, vol. 91, no 2, pp. 33-49. Disponible en Internet (1-5-2020): https://pdfs.semanticscholar.org/3c39/df9339bef51ce35d48493dee6522077b2c 9c.pdf 